\title{
Bone Marrow Edema Syndrome, Revisiting a Forgotten Entity
}

\author{
Anshul Sobti1 (1), Joel James', Shyam Sobti², Rohit Reddy Pala Bhaskar'1, \\ Ahmad Wais Osmani' ${ }^{1}$, Joseph E. Sudhakar ${ }^{3}$ \\ ${ }^{1}$ Rowley Bristow Unit, Trauma \& Orthopaedics, Ashford \& St Peter's Hospitals NHS Foundation Trust, \\ Guilford Road, Lyne, UK \\ ${ }^{2}$ Department of Radiology, Dr. D Y Patil Medical College, Navi Mumbai, India \\ ${ }^{3}$ Trauma \& Orthopaedics, Darlington Memorial Hospital, Darlington, UK \\ Email: anshulsobti@gmail.com
}

How to cite this paper: Sobti, A., James, J., Sobti, S., Bhaskar, R.R.P., Osmani, A.W. and Sudhakar, J.E. (2020) Bone Marrow Edema Syndrome, Revisiting a Forgotten Entity. Open Journal of Orthopedics, 10, 21-24.

https://doi.org/10.4236/ojo.2020.102004

Received: December 15, 2019

Accepted: January 10, 2020

Published: January 13, 2020

Copyright (C) 2020 by author(s) and Scientific Research Publishing Inc. This work is licensed under the Creative Commons Attribution International License (CC BY 4.0).

http://creativecommons.org/licenses/by/4.0/

\begin{abstract}
Bone marrow edema is a self-limiting, under-recognized condition. It mainly involves the lower limbs. It is characterized by pain and inability to bear weight. Diagnosis is most often based on imaging and by excluding other causes. Its exact pathogenesis is still debated and various theories are postulated. Treatment ranges from anti-inflammatories to restricted weight bearing. This overview has tried to revisit this rare and perhaps forgotten clinical-radiological condition.
\end{abstract}

\section{Keywords}

Bone Marrow Edema Syndrome, BMES, BME, Transient Osteoporosis, Regional Migratory Osteoporosis, Regional Osteoporosis

\section{Introduction}

Transient osteoporosis is a rare, self-limiting and under-diagnosed forgotten entity. In the past 40 years, over 800 cases of transient osteoporosis have been reported as case reports of a single case or a few cases [1]. The first clinical report of transient osteoporosis was described in the hip and it was by Curtis and Kincaid in 1959 [2]. Lequesne went on to describe it further. It was subsequently reported that similar clinical and radiographic patterns were also observed to occur in the knee, ankle and tibial shaft [3]. In the upper limb, shoulder is most commonly involved. Some patients develop this at multiple sites and on a recurrent basis and that has been described as regional migratory osteoporosis. Although rare, it can also involve different sites of the same bone around a joint 
[4].

Recently Hofmann combined all such clinical conditions together using the general term bone marrow edema syndrome (BMES) [5]. BMES is a benign clinical entity characterized by common image findings. It includes various clinical entities like transient osteoporosis of the hip (TOH), regional migratory osteoporosis (RMO), osteoporosis, migratory osteoporosis, idiopathic osteoporosis, regional osteoporosis, transient epiphyseal lesion, shifting bone marrow edema, regional migratory osteoporosis, spontaneous osteonecrosis, subchondral insufficiency fracture and algodystrophy [5] [6].

\section{Etiology}

The cause of transient regional osteoporosis is uncertain. There are various etio-pathogenesis theories described, ranging from vasomotor response similar to reflex sympathetic dystrophy, neurogenic compression, and venous obstruction to localized hyperemia [7]. One theory is that edema results from micro trauma of trabecular bone [8]. Turner et al. proposed a theory similar to osteonecrosis [9]. Authors report that the most frequent risk factor was overuse of the joint and the second commonest risk factor was bone metabolism disorders [1]. The other possible risk factors were heavy smokers and patients with previous episodes [1].

\section{Clinical Presentation \& Prognosis}

Patients with BMES present with limited range of motion and pain of sudden onset, most commonly in absence of true trauma. Most of the cases are under-diagnosed idiopathic conditions affecting healthy middle-aged men and pregnant women usually in the third trimester presenting with functional disability out of proportion to clinical examination [5]. The pain reaches its maximum at around 2 months, to the point where the patient is unable to walk and weight-bear and has limited range of movement. After 3 - 9 months the symptoms subside, but they can recur at a neighboring joint and sometimes at the same joint [5] [8] [10] [11]. The condition is self-limiting and has a favorable prognosis [5] [12] [13].

\section{Imaging}

Various studies simulate the everyday clinical practice scene that plain radiographs may be normal or inconclusive and the time between the onset of symptoms and imaging can be quite variable [7]. Radiographically, there is often diffuse osteopenia. Diagnosis is often can made after ruling out avascular necrosis, infection and stress fractures [14]. Magnetic resonance imaging (MRI) is very sensitive in depicting marrow abnormalities due to its ability to distinguish fat from other tissues. It can detect changes as early as 48 hours after onset. In the hip, both the femoral head and neck show decreased signal on T1-weighted images and an increased signal on T2-weighted images [15] [16]. Authors postulate 
that the bone marrow edema syndrome is the MRI equivalent of transient osteoporosis, diagnosed prior to the development of osteopenia. Scintigraphy always shows intense diffuse tracer uptake adjacent to the affected joint [11].

\section{Treatment}

Treatment is usually conservative, including protected weight bearing, physical therapy and use of non-steroidal analgesics [13]. BMES is a self-limiting disease with unknown etiology. Some authors advocate use of calcitonin and intravenous bisphosphonates [17]. There are reports of using prostacyclin analogues as they provide pain relief and rapid regression of the bone edema by dilating vessels and reducing permeability of capillaries [18]. Core decompression is not an uncommon surgical treatment option The hypothesis is that the pain of transient osteoporosis/BMES is partly caused by raised intra-medullary pressures, surgical procedure allows decompression of the surrounding marrow [4] [12].

\section{Conclusions}

BMES is an uncommon and self-limiting clinical entity.

Exact cause is uncertain, many theories exist.

$>$ It usually affects pregnant women and healthy middle-aged men, although other age groups can be affected. MRI is the investigation of choice.

Treatment is conservative, simple analgesia and rest.

\section{Conflicts of Interest}

The authors declare no conflicts of interest regarding the publication of this paper.

\section{References}

[1] Trevisan, C., Klumpp, R. and Compagnoni, R. (2016) Risk Factors in Transient Osteoporosis: A Retrospective Study on 23 Cases. Clinical Rheumatology, 35, 2517-2522. https://doi.org/10.1007/s10067-016-3228-7

[2] Curtiss, P. and Kincaid, W. (1959) Transitory Demineralization of the Hip in Pregnancy. A Report of Three Cases. The Journal of Bone and Joint Surgery. American Volume, 41-A, 1327-1333. https://doi.org/10.2106/00004623-195941070-00014

[3] Tsh, K., Tn, R. and Steirman, M. (2017) Transient Osteoporosis of the Hip in a Middle-Aged Male Construction Worker. The Journal of Rheumatology, 44, 258. https://doi.org/10.3899/jrheum.160934

[4] Horiuchi, K., Shiraga, N., Fujita, N., Yamagishi, M. and Yabe. H. (2004) Regional Migratory Osteoporosis: A Case Report. Journal of Orthopaedic Science, 9, 178-181. https://doi.org/10.1007/s00776-003-0758-Z

[5] Korompilias, A.V., Karantanas, A.H., Lykissas, M.G. and Beris, A.E. (2009) Bone Marrow Edema Syndrome. Skeletal Radiology, 38, 425-436. https://doi.org/10.1007/s00256-008-0529-1

[6] Aigner, N., Petje, G., Steinboeck, G., Schneider, W., Krasny, C. and Landsiedl, F. (2001) Treatment of Bone-Marrow Oedema of the Talus with the Prostacyclin Analogue Iloprost. An MRI-Controlled Investigation of a New Method. The Journal 
of Bone and Joint Surgery. British Volume, 83, 855-888. https://doi.org/10.1302/0301-620X.83B6.0830855

[7] McCarthy, E.F. (1998) The Pathology of Transient Regional Osteoporosis. Iowa Orthopedic Journal, 18, 35-42.

[8] Malizos, K.N., Karantanas, A.H., Varitimidis, S.E., Dailiana, Z.H., Bargiotas, K. and Maris, T. (2007) Osteonecrosis of the Femoral Head: Etiology, Imaging and Treatment. European Journal of Radiology, 63, 16-28.

https://doi.org/10.1016/j.ejrad.2007.03.019

[9] Turner, D.A., Templeton, A.C., Selzer, P.M., Rosenberg, A.G. and Petasnick, J.P. (1989) Femoral Capital Osteonecrosis: MR Finding of Diffuse Marrow Abnormalities without Focal Lesions. Radiology, 171, 135-140. https://doi.org/10.1148/radiology.171.1.2928517

[10] Doury, P. (1994) Bone-Marrow Oedema, Transient Osteoporosis, and Algodystrophy. The Journal of Bone and Joint Surgery. British Volume, 76, 993-994. https://doi.org/10.1302/0301-620X.76B6.7983140

[11] Maliha, G., Morgan, J. and Vrahas, M. (2012) Transient Osteoporosis of Pregnancy. Injury, 43, 1237-1241. https://doi.org/10.1016/j.injury.2012.03.009

[12] Cahir, J.G. and Toms, A.P. (2008) Regional Migratory Osteoporosis. European Journal of Radiology, 67, 2-10. https://doi.org/10.1016/j.ejrad.2008.01.051

[13] Wambeek, N., Munk, P.L., Lee, M.J. and Meek, R.N. (2000) Intra-Articular Regional Migratory Osteoporosis of the Knee. Skeletal Radiology, 29, 97-100. https://doi.org/10.1007/s002560050018

[14] Karantanas, A.H., Drakonaki, E., Karachalios, T., Korompilias, A.V. and Malizos, K. (2008) Acute Non-Traumatic Marrow Edema Syndrome in the Knee: MRI Findings at Presentation, Correlation with Spinal DEXA and Outcome. European Journal of Radiology, 67, 22-33. https://doi.org/10.1016/j.ejrad.2008.01.053

[15] Malizos, K.N., Zibis, A.H., Dailiana, Z. and Hantes, M. (2004) MR Imaging Findings in Transient Osteoporosis of the Hip. European Journal of Radiology, 50, 238-244. https://doi.org/10.1016/j.ejrad.2004.01.020

[16] Minutoli, F., Gaeta, M., Bottari, A. and Blandino, A. (2006) MRI Findings in Regional Migratory Osteoporosis of the Knee Migrating from the Femur to the Tibia. Clinical Imaging, 30, 428-430. https://doi.org/10.1016/j.clinimag.2006.05.032

[17] Varenna, M., Zucchi, F., Binelli, L., Failoni, S., Gallazzi, M. and Sinigaglia, L. (2002) Intravenous Pamidronate in the Treatment of Transient Osteoporosis of the Hip. Bone, 31, 96-101. https://doi.org/10.1016/S8756-3282(02)00812-8

[18] Aigner, N., Petje, G., Schneider, W., Krasny, C., Grill, F. and Landsiedl, F. (2002) Juvenile Bone-Marrow Oedema of the Acetabulum Treated by Iloprost. The Journal of Bone and Joint Surgery. British Volume, 84, 1050-1052.

https://doi.org/10.1302/0301-620X.84B7.0841050 